\title{
Demokratie im Mehrebenensystem: Integrationsfest oder integrationsoffen?
}

\author{
Überlegungen zum Demokratiebegriff im Lissabon-Urteil des BVerfG \\ im Lichte des Schmitt-Kelsen-Gegensatzes
}

Shu-Perng Hwang*
A. Problemstellung .
166
B. Die Demokratievorstellung des BVerfG im Lissabon-Urteil: Europarechts- freundlich und doch integrationsfest. . 168
C. Die integrationsfeste Verfassungsiden- tität zur Gewährleistung der demokra- tischen Selbstbestimmung: Zur Wie- derbelebung der Schmittschen Demo- kratiekonzeption im Lissabon-Urteil . 170
D. Die integrationsfeste Verfassungsiden- tität im Kampf gegen den normativen Universalismus: Zur Abkehr vom Kel- senschen Demokratiebegriff durch das Lissabon-Urteil...................... 179
E. Demokratie und europäische Integra- tion aus Sicht der Demokratie- und Völkerrechtstheorie Kelsens ........... 186
F. Schlussbemerkung .................. 190

\section{A. Problemstellung}

Im Lissabon-Urteil des Bundesverfassungsgerichts wird die Grundfrage behandelt, wie im europäischen Mehrebenensystem das Demokratieprinzip zu verstehen und zu gewährleisten ist. Dabei beschäftigt sich das BVerfG sowohl mit den prozessualen als auch mit den substantiellen Dimensionen der demokratischen Selbstbestimmung und weist mit Nachdruck darauf hin, die europäische Integration dürfe nicht „zur einer Aushöhlung des demokratischen Herrschaftssystems in Deutschland führen “. ${ }^{1}$ Demzufolge bedeute einerseits die Wahrung der Souveränität „nicht, dass eine von vornherein bestimmbare Summe oder bestimmte Arten von Hoheitsrechten in der Hand des Staates bleiben müssten. "2 Andererseits dürfe die europäische Vereinigung „nicht so verwirklicht werden, dass in den Mitgliedstaaten kein ausreichender Raum zur politischen Gestaltung der wirtschaftlichen, kulturellen und sozialen Lebensverhältnisse mehr bleibt.“3

Diese Aussagen machen zwar deutlich, dass das BVerfG zwischen der nationalen demokratischen Willensbildung und der supranationalen bzw. europäischen Integration einen Ausgleich finden will. Der daraus gezogene Schluss, einige Sachbereiche seien „besonders sensibel für die demokratische Selbstgestaltungsfähigkeit eines Verfassungsstaates“ und müssten daher für „integrationsfest“ gehalten werden, deutet allerdings wohl darauf hin, dass das BVerfG trotz allem von dem Spannungsverhältnis zwischen Demokratiewahrung und Europäisierung ausgeht. Auch abgesehen davon, ob diese Voraussetzung überhaupt berechtigt ist, verdient sie schon deshalb

\footnotetext{
* Prof. Dr. Shu-Perng Hwang ist Forschungsprofessorin am Institutum Iurisprudentiae, Academia Sinica, Taipeh/Taiwan..

1 BVerfGE 123, 267 (356).

2 BVerfGE 123, 267 (357).

3 BVerfGE 123, 267 (357f.).
} 
Beachtung, weil ihr eine bestimmte Demokratiekonzeption zugrunde liegen müsste, die erst eine „sachliche Begrenzung“ der Übertragung und Ausübung von Hoheitsrechten auf die EU begründet.

Die vorliegende Arbeit interessiert sich daher für die Frage, auf welcher Erkenntnisgrundlage das BVerfG sich an einem „integrationsfesten Demokratiebegriff“ orientiert hat. Vor allem interessiert die vorliegende Arbeit, ob oder inwiefern das Demokratieverständnis des BVerfG im Rahmen des europäischen Mehrebenensystems die frühere, insbesondere aber die Schmitt-Kelsen-Debatte um den Demokratiebegriff ${ }^{4}$ in dem Sinne wiederbelebt hat, dass gerade diese zur Auseinandersetzung über die Natur des Völkerrechts veranlasst und insoweit dazu beigetragen hat, das Verhältnis zwischen nationaler und supranationaler Rechtsordnung aus demokratischer Perspektive zu beleuchten. ${ }^{5}$

Im Folgenden wird also zunächst klargestellt, was in der Lissabon-Entscheidung das BVerfG unter Demokratie bzw. demokratischer Selbstbestimmung versteht (B). Sodann wird untersucht, ob und in welchem Sinne der Demokratiebegriff beim Lissabon-Urteil sich unter dem Einfluss der Demokratiekonzeption von Carl Schmitt entwickelt hat ${ }^{6}(\mathrm{C})$. Daran anschließend soll gezeigt werden, weshalb bzw. mit welchem Demokratieverständnis das BVerfG sich von der Demokratie- sowie von der Völkerrechtstheorie Hans Kelsens unterscheidet und sich infolgedessen gegen eine (Kelsensche) monistische Konstruktion der europäischen Rechtsordnung richtet (D). Schließlich taucht dann die Überlegung auf, ob und wie der Gegensatz von demokratischer Selbstbestimmung und europäischer Integration sich durch den Kelsenschen Ansatz überwinden lässt (E).

4 Zur Aktualität dieser Weimarer Debatte auch im Blick auf die Entwicklung des europäischen Mehrebenensystems vgl. an dieser Stelle nur H. Sauer, Von Weimar nach Lissabon? Zur Aktualität des Methoden- und Richtungsstreits der Weimarer Staatsrechtslehre bei der Bewältigung von Europäisierung und Internationalisierung des öffentlichen Rechts, in: U. J. Schröder/A. v. Ungern-Sternberg (Hrsg.), Zur Aktualität der Weimarer Staatsrechtslehre, 2011, S. 237 (244 ff., 251 f., 256 ff.).

5 Selbstverständlich deutet die Fokussierung auf den Schmitt-Kelsen-Gegensatz keineswegs darauf hin, dass das Demokratieverständnis beim Lissabon-Urteil erst im Lichte der Gegenüberstellung zwischen Schmitt und Kelsen oder radikaler nur durch den Rückgriff auf Schmitt aufzufassen ist. Vielmehr spielt hier die Schmitt-Kelsen-Debatte deshalb eine instruktive Rolle, weil sie - dank der umfangreichen Lehren sowohl bei Schmitt als auch bei Kelsen, die rechtstheoretische, demokratische und völkerrechtliche Dimensionen umfassen - in der Lage ist, die (staatszentrierte) Stellungnahme des BVerfG konsequent zu beleuchten. Auch schon an dieser Stelle soll geklärt werden, dass nach Ansicht der vorliegenden Arbeit die Lehre Schmitts sich nicht auf dessen nationalsozialistische Ideologie reduzieren lässt, wie gelegentlich behauptet wird. In diesem Zusammenhang fungiert Schmitt niemals als „Label“, sondern trägt mit seiner voraussetzungsvollen und insofern durchaus originalen Demokratietheorie zur Erklärung dafür bei, aus welchen staatstheoretischen bzw. demokratischen Vorverständnissen sich die Vorstellung integrationsfester Verfassungsidentität ergibt und wie diese Vorstellung zu Lasten der europäischen Integration wirken würde.

6 Nur am Rande soll vermerkt werden, dass sich die vorliegende Studie bei der Untersuchung des Demokratisverständnisses des BVerfG überwiegend auf die Analyse des Lissabon-Urteils beschränkt. Daher befasst sie sich nicht mit der Frage, ob und inwiefern die Rechtsprechung des BVerfG nach der LissabonEntscheidung eine andere Demokratievorstellung zum Ausdruck bringt. 


\section{B. Die Demokratievorstellung des BVerfG im Lissabon-Urteil: Europarechtsfreundlich und doch integrationsfest}

Wie bereits angedeutet wurde, hält das BVerfG im Lissabon-Urteil trotz der Herausstellung des „Grundsatzes der Europarechtsfreundlichkeit“ deutlich an der „Unantastbarkeit“ der innerstaatlichen demokratischen Selbstbestimmung fest. Es betont infolgedessen nicht nur, dass der subjektive Anspruch der Staatsbürger auf demokratische Teilhabe wirksam bleiben muss, ${ }^{7}$ sondern auch, dass die souverän bleibenden Mitgliedstaaten „ihre Fähigkeit zu selbstverantwortlicher politischer und sozialer Gestaltung der Lebensverhältnisse nicht verlieren "8 dürfen:

„Die ,Verfassung Europas‘, das Völkervertrags- oder Primärrecht, bleibt eine abgeleitete Grundordnung. Sie begründet eine im politischen Alltag durchaus weitreichende, aber immer sachlich begrenzte überstaatliche Autonomie. "9

Von daher weist das BVerfG darauf hin, die Ausgestaltung der Europäischen Union müsse „demokratischen Grundsätzen entsprechen“, wobei die europäische Integration nicht „zu einer Aushöhlung des demokratischen Herrschaftssystems in Deutschland führen " dürfe. ${ }^{10}$ Merkwürdig ist dabei, dass das BVerfG hier nach Maßgabe des Art. 79 Abs. 3 GG nicht lediglich die „unübertragbare und insoweit integrationsfeste Identität der Verfassung " 11 hervorhebt, sondern darüber hinaus bestimmte Sachbereiche als demokratisch sensible und infolgedessen sachlich-inhaltlich integrationsfeste Regelungsgegenstände in den Mittelpunkt stellt:

„Die europäische Vereinigung auf der Grundlage einer Vertragsunion souveräner Staaten darf allerdings nicht so verwirklicht werden, dass in den Mitgliedstaaten kein ausreichender Raum zur politischen Gestaltung der wirtschaftlichen, kulturellen und sozialen Lebensverhältnisse mehr bleibt. Dies gilt insbesondere für Sachbereiche, die die Lebensumstände der Bürger, vor allem ibren von den Grundrechten geschützten privaten Raum der Eigenverantwortung und der persönlichen und sozialen Sicherheit prägen, sowie für solche politische Entscheidungen, die in besonderer Weise auf kulturelle, historische und sprachliche Vorverständnisse angewiesen sind, und die sich in parteipoli-

7 Vgl. BVerfGE 123, 267 (340 ff.). Dies gilt umso mehr, wenn es sich um die „Souveränitätsübertragung auf ein neues Legitimationssubjekt“ handelt: „Das Grundgesetz ermächtigt die für Deutschland handelnden Organe nicht, durch einen Eintritt in einen Bundesstaat das Selbstbestimmungsrecht des Deutschen Volkes in Gestalt der völkerrechtlichen Souveränität Deutschlands aufzugeben. Dieser Schritt ist wegen der mit ihm verbundenen unwiderruflichen Souveränitätsübertragung auf ein neues Legitimationssubjekt allein dem unmittelbar erklärten Willen des Deutschen Volkes vorbehalten." BVerfGE 123, 267 (347f.). Dazu kritisch K. F. Gärditz/C. Hillgruber, Volkssouveränität und Demokratie ernst genommen - Zum Lissabon-Urteil des BVerfG, JZ 2009, S. 872 (875 f.).

8 BVerfGE 123, 267 (347).

9 BVerfGE 123, 267 (349).

10 BVerfGE 123, 267 (356).

11 BVerfGE 123, 267 (350). 
tisch und parlamentarisch organisierten Raum einer politischen Öffentlichkeit diskursiv entfalten. Zu wesentlichen Bereichen demokratischer Gestaltung gehören unter anderem die Staatsbürgerschaft, die zivile und militärische Gewaltmonopol, Einnahmen und Ausgaben einschließlich der Kreditaufnahme sowie die für die Grundrechtsverwirklichung maßgeblichen Eingriffstatbestände, vor allem bei intensiven Grundrechtseingriffen wie dem Freiheitsentzug in der Strafrechtspflege oder bei Unterbringungsmaßnabmen. Zu diesen bedeutsamen Sachbereichen gehören auch kulturelle Fragen wie die Verfügung über die Sprache, die Gestaltung der Familien- und Bildungsverhältnisse, die Ordnung der Meinungs-, Presse- und Versammlungsfreiheit oder der Umgang mit dem religiösen oder weltanschaulichen Bekenntnis. "12

Um die Identitätsrelevanz der genannten Sachbereiche näher zu begründen, verweist das BVerfG weiterhin darauf, eine wirksame Demokratie setze die „funktionsfähige öffentliche Meinung“ voraus, wobei „die öffentliche Wahrnehmung von Sachthemen und politischem Führungspersonal in erheblichem Umfang an nationalstaatliche, sprachliche, historische und kulturelle Identifikationsmuster angeschlossen bleibt." ${ }^{13}$ Demzufolge führt das Gericht aus:

„Sowobl das Demokratieprinzip als auch das ebenfalls von Art.23 Abs. 1 Satz 1 GG strukturell geforderte Subsidiaritätsprinzip verlangen deshalb, gerade in zentralen politischen Bereichen des Raums persönlicher Entfaltung und sozialer Gestaltung der Lebensverhältnisse, die Übertragung und die Ausübung von Hoheitsrechen auf die Europäische Union in vorhersehbarer Weise sachlich zu begrenzen. In diesen Bereichen bietet es sich in besonderem Maße an, die Grenzlinie dort zu ziehen, wo die Koordinierung grenzüberschreitender Sachverhalte sachlich notwendig ist. "14

Bereits diesen Ausführungen ist zu entnehmen, dass der Lissabon-Entscheidung ein inhaltsbestimmter Demokratiebegriff zugrunde liegt. Dieser zeichnet sich nicht nur durch die Voraussetzung der herkömmlichen Gegenüberstellung von Recht und Politik aus, wobei Demokratie sich überwiegend auf einen bestimmten Raum für politische Gestaltung bezieht, sondern vielmehr durch die Vorstellung, wonach es keine Demokratie ohne (sich nach außen abgrenzende) Identität gibt. Genau dies führt das BVerfG einerseits zur Hervorhebung der demokratischen Sensibilität der genannten identitätsrelevanten Sachverhalte, andererseits auch zu der nationalstaats- bzw. souveränitätszentrierten ${ }^{15}$ Annahme, dass

15 Vgl. auch A. v. Bogdandy, Prinzipien der Rechtsfortbildung im europäischen Rechtsraum. Überlegungen zum Lissabon-Urteil des BVerfG, NJW 2010, S. 1 (2 f.). 
„auf mitgliedstaatlicher Ebene sowobl im Umfang als auch in der Substanz noch Aufgaben von hinreichendem Gewicht bestehen [müssen], die rechtlich und praktisch Voraussetzung für eine lebendige Demokratie sind."16

So gesehen liegt es nahe, dass das BVerfG sich auf den ersten Blick zwar darum bemüht, der Politik rechtliche Grenzen zu ziehen, indem es genau am Maßstab des Grundgesetzes die politische Gestaltungsfreiheit im Wege der europäischen Integration einschränkt. ${ }^{17}$ Eine nähere Betrachtung zeigt jedoch, dass bereits seiner Auslegung des Grundgesetzes ein politisches Vorverständnis für das Demokratieprinzip innewohnt. ${ }^{18}$ Mit anderen Worten: Die integrationsfeste, „verordnete“ Demokratie ${ }^{19}$ ergibt sich nicht aus dem Grundgesetz selbst, sondern aus der vom BVerfG vorausgesetzten, politischen Demokratiekonzeption.

\section{Die integrationsfeste Verfassungsidentität zur Gewährleistung der demokratischen Selbstbestimmung: Zur Wiederbelebung der Schmittschen Demokratiekonzeption im Lissabon-Urteil}

Die vorstehende Betrachtung weist weder darauf hin, dass der Demokratiebegriff beim Lissabon-Urteil gar keine normativen Demokratieverständnisse enthält, noch darauf, dass das BVerfG eine Demokratietheorie vertreten würde, die sich im Kampf gegen die europäische Union und insofern gegen die „offenen Staaten“ entfalten soll. In der Tat hat das BVerfG, wie gezeigt, doch die normative Bedeutung des Demokratieprinzips in den Vordergrund gerückt, indem es ausführte: „Der Anspruch auf

16 BVerfGE 123, 267 (406).

17 Vgl. C. Obler, Herrschaft, Legitimation und Recht in der europäischen Union - Anmerkungen zum Lissabon-Urteil des BVerfG, AöR 135 (2010), S. 153 (172); C. D. Classen, Legitime Stärkung des Bundestages oder verfassungsrechtliches Prokrustesbett?, JZ 2009, S. 881 (889); C. Franzius, Vom Nationalstaat zum Mitgliedstaat und wieder zurück? Modifikationen „offener Staatlichkeit“ durch das Lissabon-Urteil des Bundesverfassungsgerichts, Leviathan 38 (2010), S. 429 (437); kritisch M. Nettesheim, Ein Individualrecht auf Staatlichkeit? Die Lissabon-Entscheidung des BVerfG, NJW 2009, S. 2867 (2868).

18 Im Ansatz auch J. Schwarze, Die verordnete Demokratie. Zum Urteil des 2. Senats des BVerfG zum Lissabon-Vertrag, EuR 2010, S. 108 (112); M. Jestaedt, Warum in die ferne Schweifen, wenn der Maßstab liegt so nah? Verfassungshandwerkliche Anfragen an das Lissabon-Urteil des BVerfG, Der Staat 48 (2009), S. 497 (510) („Überspielung der positivrechtlichen Verfassung durch die senatseigene Staatstheorie“); C. Schönberger, Die Europäische Union zwischen „Demokratiedefizit“ und Bundesstaatsverbot. Anmerkungen zum Lissabon-Urteil des Bundesverfassungsgerichts, Der Staat 48 (2009), S. 535 (551) („Fragwürdige Staatstheorie statt Verfassungsrechtsdogmatik“). Dies zeigt sich schon dadurch, dass die Kritik an der verfassungsgerichtlichen Entwicklung der bezeichneten Vorbehaltsbereiche gemeinsam darauf hinweist, vom Grundgesetz her seien diese integrationsfesten Bereiche kaum abzuleiten. Vgl. z. B. v. Bogdandy, Prinzipien (Fn. 15), S. 3; M. Ruffert, An den Grenzen des Integrationsverfassungsrechts: Das Urteil des Bundesverfassungsgerichts zum Vertrag von Lissabon, DVB1. 2009, S. 1197 (1204); M. Nettesheim, Die Karlsruher Verkündigung - Das BVerfG in staatsrechtlicher Endzeitstimmung, in: A. Hatje/J. P. Terhechte (Hrsg.), Grundgesetz und europäische Integration, EuR Beiheft 1/2010, S. 101 (114 f.); Obler, Herrschaft (Fn. 17), S. 175; M. Herdegen, Europarecht, 13. Aufl. 2011, S. 221; vgl. auch Nettesheim, Individualrecht (Fn. 17), S. 2868.

19 Terminologisch vgl. Schwarze, Demokratie (Fn. 18), S. 108. 
freie und gleiche Teilhabe an der öffentlichen Gewalt ist in der Würde des Menschen (Art. 1 Abs. 1 GG) verankert";20 und:

„Obne freie und gleiche Wahl desjenigen Organs, das einen bestimmenden Einfluss auf die Regierung und Gesetzgebung des Bundes hat, bleibt das konstitutive Prinzip personaler Freibeit unvollständig. "21

Mit der Herausstellung der grundrechtlichen Dimensionen der Demokratie ${ }^{22}$ machte das BVerfG klar, dass das grundgesetzliche Demokratieprinzip sich von vornherein keineswegs gegen die offene Staatlichkeit richtet. Doch ist dabei nicht zu verleugnen, dass (auch) dieses normative Demokratieverständnis eng mit der politischen Funktion der Demokratie zusammenhängt. Nach dem Lissabon-Urteil ist die Stellung des Bundestags deshalb zu verstärken, weil dieser die demokratische Willensbildung realisiert und auf diese Weise den subjektiven Anspruch der Bürger auf demokratische Teilhabe geltend macht. Gerade deswegen aber müsste die durch die parlamentarische Willensbildung zu verwirklichende demokratische Selbstbestimmung die „integrationsfeste Verfassungsidentität" voraussetzen und sich in diesem Sinne auf der Basis einer identitätsbezogenen Abgrenzung entfalten, um die Achtung der Menschenwürde zur Geltung bringen zu können. Genau im Lichte dieser politischen Funktion des Demokratieprinzips liegt die Feststellung nicht nur der Unübertragbarkeit der Kompetenz-Kompetenz, ${ }^{23}$ sondern auch des begrenzten Anwendungsvorrangs des Unionsrechts ${ }^{24}$ nahe.

Die vom BVerfG hervorgehobenen integrationsfesten Regelungsgegenstände lassen sich erst aus diesem politischen Demokratieverständnis ableiten. Trotz der Europarechtsfreundlichkeit ${ }^{25}$ hält die Lissabon-Entscheidung daran fest, dass den Mitgliedstaaten „ausreichender Raum zur politischen Gestaltung der wirtschaftlichen, kul-

20 BVerfGE 123, 267 (341).

21 BVerfGE 123, 267 (340).

22 Zu diesem Aspekt der Lissabon-Entscheidung vgl. auch D. Thym, Europäische Integration im Schatten souveräner Staatlichkeit. Anmerkungen zum Lissabon-Urteil des Bundesverfassungsgerichts, Der Staat 48 (2009), S. 559 (584); G. Britz, Vom kulturellen Vorbehalt zum Kulturvorbehalt in der bundesverfassungsgerichtlichen Demokratietheorie des Lissabon-Urteils?, in: Hatje/Terhechte (Hrsg.), Grundgesetz (Fn. 18), S. $151(165,167)$.

23 Vgl. BVerfGE 123, 267 (349). Dies erinnert an die herkömmliche Gegenüberstellung zwsichen der Übertragung von Hoheitsrechten und von Souveränität, wobei häufig von der Unteilbarkeit der Souveränität gesprochen wird. Vgl. nur U. Di Fabio, Der Verfassungsstaat in der Weltgesellschaft, 2001, S. 92: „Eine ,Teilung‘ der Souveränität ist danach nicht möglich, ohne den Begriff um seinen Sinn zu bringen. Gemeint ist häufig auch ganz etwas anderes: Teilung der Hoheitsrechte, der Kompetenzen, gemeinsame und insofern geteilte Verantwortung verschiedener Ebenen und Gemeinschaftten, die aber aufeinander schauen, sich binden und zu einer grundlegend neuen Identität offener Herrschaft zusammenwachsen." (Hervorhebung im Original).

24 Vgl. BVerfGE 123, 267 (354).

25 Zur Herausstellung und positiven Bewertung dieses Aspektes des Lissabon-Urteils vgl. vor allem F. C. Mayer, Europarechtsfreundlichkeit und Europarechtsskepsis in der Rechtsprechung des Bundesverfassungsgerichts, in: T. Giegerich (Hrsg.), Der „offene Verfassungsstaat“ des Grundgesetzes nach 60 Jahren, 2010, S. 237 (264 ff.). 
turellen und sozialen Lebensverhältnisse “ bleiben muss. Dieser bezieht sich, wie gezeigt, nicht nur auf die prozessualen, sondern darüber hinaus auf die inhaltlichen Aspekte der demokratischen Selbstbestimmung. Dabei konzentriert sich das BVerfG auf „nationalstaatliche, sprachliche, historische und kulturelle Identifikationsmuster", die gemeinsam auf das enge Verhältnis zwsichen Homogenität und Demokratie hindeuten ${ }^{26}$ und insofern für die Homogenitätsanforderungen der Demokratie sprechen. ${ }^{27}$ Daher betont das BVerfG: Die Strafrechtspflege sei „von kulturellen, historisch gewachsenen, auch sprachlich geprägten Vorverständnissen und von den im deliberativen Prozess sich bildenden Alternativen abhängig, die die jeweilige öffentliche Meinung bewegen "; der konstitutive Parlamentsvorbehalt für den Auslandseinsatz der Bundeswehr sei „integrationsfest“; im Bereich des Haushaltsrechts obliege „gerade die sozialpolitische Verantwortung dem demokratischen Entscheidungsprozess“; das Sozialstaatsprinzip setze „notwendig die politische und rechtliche Konkretisierung voraus“, weswegen „die sozialpolitisch wesentlichen Entscheidungen in eigener Verantwortung der deutschen Gesetzgebungsorgane getroffen werden“ müssten; und schließlich sei demokratische Selbstbestimmung „auf die Möglichkeit, sich im eigenen Kulturraum verwirklichen zu können, besonders angewiesen bei Entscheidungen, wie die insbesondere im Schul- und Bildungssystem, im Familienrecht, bei der Sprache, in Teilbereichen der Medienordnung und zum Status von Kirchen, Religions- und Weltanschauungsgemeinschaften getroffen werden. “28 Diese Aussagen schließen zwar keine inhaltsfesten Entscheidungen aus, gehen aber gemeinsam davon aus, dass in bestimmten Sachbereichen nicht von Integration, sondern von Demokratie bzw. von Identitätswahrung die Rede sein soll.

26 Insoweit lässt sich sagen, dass die Lissabon-Entscheidung den „Homogenitätsansatz“ des MaastrichtUrteils (vgl. BVerfGE 89, 155 (186)) nicht in Frage stellt, sondern im Gegenteil fortgesetzt. Vgl. dazu auch J. E. K. Murkens, Identity Trumps Integration. The Lisbon Treaty in the German Federal Constitutional Court, Der Staat 48 (2009), S. 517 (521). Zum Homogenitätsansatz des Maastricht-Urteils vgl. etwa I. Pernice, Carl Schmitt, Rudolf Smend und die europäische Integration, AöR 120 (1995), S. 100 (105), wo zutreffend hervorgehoben wird, dass für die Homogenitätsbedingungen der Demokratie Carl Schmitt „die richtige Referenz wäre“, weil Hermann Heller, der in der Maastricht-Entscheidung zitiert worden ist, „primär auf den sozialen Ausgleich abzielt und nicht auf das, wofür ihn das BVerfG in Anspruch nimmt: Homogenität des Volkes als Bedingung des Staates.“ Eine ähnliche Einschätzung vertritt T. Ehs, Einführung in die Allgemeine Europäische Staatslehre, in: T. Ehs (Hrsg.), Hans Kelsen und die Europäische Union. Erörterungen moderner (Nicht-)Staatlichkeit, 2008, S. 11(13 f.); R. van Ooyen, Homogenes Staatsvolk statt EU-Bürgerschaft: Das Bundesverfassungsgericht zitiert Heller, meint Schmitt und verwirft Kelsens postnationales Konzept demokratischer Rechtsgenossenschaft, in: ders., Hans Kelsen und die offene Gesellschaft, 2010, S. 54 (55, 61 ff.); Saner, Weimar (Fn. 4), S. 244, 250. Die erwähnte Literatur weist gemeinsam darauf hin, dass Schmitts Demokratietheorie vor allem im Sinne der Homogenitätsvoraussetzungen von originaler Bedeutung ist. Gerade deswegen lässt sich die Stellungnahme des Lissabon-Urteils wohl auf Schmitt zurückführen.

27 So auch Murkens, Identity (Fn. 26), S. 530; C. Möllers, Fragmentierung als Demokratieproblem?, in: C. Franzius/F. C. Mayer/J. Neyer (Hrsg.), Strukturfragen der Europäischen Union, 2010, S. 150 (151). Vgl. aber Thym, Integration (Fn. 22), S. 581; Britz, Vorbehalt (Fn. 22), S. 165, wo angenommen wird, dass das Lissabon-Urteil auf die Homogenitätsthese verzichtet hat. 
Schon an dieser Stelle veranschaulicht sich, dass nach dem BVerfG ein Spannungsverhältnis zwischen europäischer Integration und demokratischer Selbstbestimmung darin besteht, dass Demokratie ein Mindestmaß an Homogenität voraussetzen muss, die sich durch kulturelle, historische und sprachliche Gemeinsamkeiten darstellt. Die Signalisierung der genannten integrationsfesten Regelungsbereiche dient insofern nicht nur zur Geltendmachung demokratischer Selbstbestimmung, sondern ferner zur Sicherstellung der sich nach außen abgrenzenden Homogenität. Erst dadurch „bleibt eine lebendige demokratische Öffentlichkeit innerstaatlich sachlich möglich “. ${ }^{29}$ Demgegenüber konstituiert die Unionsbürgerschaft nach Ansicht des BVerfG deshalb „kein Unionsvolk“, weil - demokratisch betrachtet - die Unionsbürger wegen Mangels an Homogenität nicht in der Lage seien, sich „zur eigenen Selbstbestimmung “ zu berufen. ${ }^{30}$ Dieses von Homogenität geprägte und insoweit nationalstaatszentrierte Demokratieverständnis verdankt sich zwar dem Gedanken, dass der Nationalstaat „der entscheidende Garant für die Freiheit, Sicherheit und die Möglichkeit von Wohlstand [bleibt]“..31

Die daraus folgende Überzeugung, im Interesse der innerstaatlichen demokratischen Selbstbestimmung sei eine identitätsverletzende Europäisierung abzuwehren, reicht jedoch schon weit über das Vertrauen in die parlamentarische Demokratie der Bundesrepublik Deutschland hinaus. Vielmehr beruht die Vorstellung integrationsfester Identität auf der Annahme, erst die Identitätswahrung ermögliche eine lebendige Demokratie; genau deswegen müsse sich die Demokratie auf die Homogenität stützen, denn nur so lasse sich die nach außen abgrenzbare und daher effektive demokratische Selbstbestimmung gewährleisten. Gerade dieses homogenitätsorientierte Demokratieverständnis gerät im Wege der europäischen Integration in ein Paradox: Während dieses an einer homogenitätsbezogenen Abgrenzung und daher an einer begrenzten bzw. „,integrationsfesten “ Europäisierung festhält, um die innerstaatliche demokratische Willensbildung vor fremden Einflüssen zu schützen, schränkt es die demokratische Selbstbestimmung doch nicht unerheblich ein, indem auch dem parlamentarischen Integrationsprogramm sachbereichsspezifische Grenzen gezogen werden, die gerade von den Homogenitätsgedanken abzuleiten sind.

Bereits an dieser Stelle zeigt sich, dass beim BVerfG eine inhaltsbestimmte, d. h. Homogenität voraussetzende Demokratie im Mittelpunkt steht. Demzufolge führt die Demokratiekonzeption des BVerfG nicht nur zwangsläufig zum prinzipiellen Gegensatz von Demokratie und Europäisierung, sondern lässt von vornherein außer

29 Di Fabio, Verfassungsstaat (Fn. 23), S. 97.

30 Vgl. BVerfGE 123, 267 (404).

31 Di Fabio, Verfassungsstaat (Fn. 23), S. 99. Vgl. zum Vertrauen des Lissabon-Urteils in die Fähigkeit des Nationalstaates zur Freiheits- und Friedenssicherung auch Nettesheim, Karlsruher Verkündigung (Fn. 18), S. 116 f.; im Blick auf den (vom BVerfG betonten) Parlamentsvorbehalt M. Kutscha, Das Parlament als Friedenswächter? Anmerkungen zum Lissabon-Urteil des Bundesverfassungsgerichts, in: P. Becker/R. Braun/D. Deiseroth (Hrsg.), Frieden durch Recht?, 2010, S. 137 (141 f.). 
acht, dass gerade im Rahmen der Europäischen Union „die Freiheit, Sicherheit und die Möglichkeit von Wohlstand“ nicht nur durch die Mitgliedstaaten allein, sondern vielmehr auch durch die Rechtsordnung des Unionsrechts - oder genauer: durch das Zusammenspiel zwischen nationalen und supranationalen Rechtsordnungen ${ }^{32}-\mathrm{zu}$ gewährleisten sind. Schon in dieser Hinsicht läuft die homogenitätsorientierte Demokratievorstellung Gefahr, die Rechtsschutzfunktion des Nationalstaates bzw. der nationalstaatlichen Demokratie zu überschätzen ${ }^{33}$ und dergestalt die (von der europäischen Rechtsordnung gebotene) Bindung nationalstaatlicher demokratischer Willensbildung an die Vorgaben des Unionsrechts zu übersehen.

Der Befund, dass vornehmlich nicht das grundgesetzlich unantastbare Demokratieprinzip nach Art. 20 Abs. 1 und Abs. 2 in Verbindung mit Art. 79 Abs. 3 GG, sondern vielmehr die Homogenität voraussetzende Demokratiekonzeption des BVerfG dessen Vorstellung des Verhältnisses zwischen dem deutschen Recht und dem Unionsrecht geprägt hat, ${ }^{34}$ erinnert an die Auseinandersetzung von Hans Kelsen und Carl Schmitt aus der Weimarer Zeit. Sowohl Kelsen als auch Schmitt entwickeln ihre Völkerrechtslehre im Lichte ihrer jeweils eigenen Demokratietheorie. Während Kelsen eine pluralistische Demokratie vertritt und auf der Grundlage von Pluralismus und Relativismus ${ }^{35}$ für die monistische Konstruktion der Völkerrechtsordnung plädiert, ${ }^{36}$ wobei die nationalstaatszentrierte Souveränität wegen des Primats der Völ-

32 Vgl. auch M. Zürn, Das Bundesverfassungsgericht und die Politisierung der Europäischen Union, in: Franzius/Mayer/Neyer (Hrsg.), Strukturfragen (Fn. 27), S. 46 (48).

33 Vgl. insofern auch Ruffert, Grenzen (Fn. 18), S. 1207.

34 Vgl. im Ergebnis auch Jestaedt, Verfassungshandwerkliche Anfragen (Fn. 18), S. 506 f., 515 f.; Murkens, Identity (Fn. 26), S. $526 \mathrm{ff}$.

35 Zum Pluralismus und Relativismus als Grundlage der Demokratietheorie Kelsens vgl. H. Kelsen, Vom Wesen und Wert der Demokratie (1929), 2. Aufl. 1963, S. S. 98 ff. Vgl. dazu ferner R. van Ooyen, Der Staat der Moderne. Hans Kelsens Pluralismustheorie, 2003, S. 70 ff.; S.-P. Hwang, Rechtsanwendung in der pluralistischen Demokratie. Hans Kelsens Verständnis der Verfassungsgerichtsbarkeit unter besonderer Berücksichtigung seiner Demokratietheorie, Der Staat 46 (2007), S. 442 (453 ff.); O. Lepsius, Kelsens Demokratietheorie, in: T. Ehs (Hrsg.), Hans Kelsen: Eine politikwissenschaftliche Einführung, 2009, S. 67 (82 ff.).

36 Zur Gegenüberstellung von monistischer und dualistischer bzw. pluralistischer Konstruktion der Völkerrechtsordnung bei Kelsen vgl. H. Kelsen, Reine Rechtslehre, Studienausgabe der 1. Aufl. 1934, 2008, S. 147 ff.; H. Kelsen, Das Problem der Souveränität und die Theorie des Völkerrechts. Beitrag zu einer Reinen Rechtslehre, 2. Neudruck der 2. Aufl. 1928, 1981, S. 120 ff.; H. Kelsen, Principles of International Law, 2. ed., 1966, S. 553 ff. Vgl. auch C. Höpfner, Die systemkonforme Auslegung. Zur Auflösung einfachgesetzlicher, verfassungsrechtlicher und europarechtlicher Widersprüche im Recht, 2008, S. 358 f. 
kerrechtsordnung ${ }^{37}$ beträchtlich relativiert wird, ${ }^{38}$ geht Schmitt bekanntlich von einer homogenen Demokratie aus, ${ }^{39}$ die folgerichtig für die Notwendigkeit der Identitätswahrung spricht und insofern die Unteilbarkeit der Staatssouveränität verstärkt begründet. ${ }^{40}$ Demzufolge handelt es sich bei der Völkerrechtstheorie von Schmitt nicht so sehr um die Gegenüberstellung zwischen monistischer und dualistischer Konstruktion der Völkerrechtsordnung, sondern vielmehr darum, wie die völkische Homogenität zur Gewährleistung der einzelnen abgrenzbaren Identität und damit zur Realisierung der völkischen Selbstbestimmung effektiv darzustellen ist. ${ }^{41}$

Aus dieser Perspektive liegt der Schluss nahe, dass das BVerfG in seinem LissabonUrteil die Schmittsche Demokratiekonzeption in dem Sinne wiederbelebt hat, dass auch die vom BVerfG vorgenommene sachbereichsspezifische Abgrenzung zugunsten der innerstaatlichen demokratischen Selbstbestimmung wohl auf eine von kulturellen, historischen, sozialen und sprachlichen Vorverständnissen abhängige Demokratievorstellung zurückzuführen ist. Bereits die Orientierung des BVerfG an einer substantiellen Grenzziehung korrespondiert mit der homogenitäts- und identitätsbewusste Aussage von Schmitt:

$37 \mathrm{Zu}$ diesem Ausgangspunkt, auf dem Kelsens Völkerrechtslehre beruht, vgl. nur Kelsen, Problem (Fn. 36), S. 151 ff., 204 ff.; Kelsen, Principles of International Law (Fn. 36), S. 573 ff.; H. Kelsen, Reine Rechtslehre. Mit einem Anhang: Das Problem der Gerechtigkeit, 2. Aufl. (1960), Nachdruck 2000, S. 339 ff., 343 ff.; H. Kelsen, Peace Through Law, 1944, S. 40 ff.

38 Diese Relativierung geht hinsichtlich der Rechts- und Staatstheorie Kelsens grundlegender auf den Ausgangspunkt zurück, dass der Staat ausschließlich als Rechtsordnung zu begreifen sei. Vgl. in diesem Zusammenhang insbesondere H. Kelsen, Staatsform und Weltanschauung (1933), in: ders., Demokratie und Sozialismus: Ausgewählte Aufsätze, 1967, S. 40 (53 f.): „Der Staat, das sind wir. Die Tendenz dieser Erkenntnis ist nicht auf Verabsolutierung, sondern umgekehrt auf Relativierung des Staates gerichtet. Sie löst den Begriff der Souveränität als Ideologie bestimmter Herrschaftsansprüche auf ....".

39 Vgl. nur C. Schmitt, Verfassungslehre (1928), 5. Aufl. 1970, S. 228 ff. Dazu ferner Pernice, Carl Schmitt (Fn. 26), S. 103 ff.; Ehs, Einführung (Fn. 26), S. 14.

40 Auf der Grundlage einer Homogenität voraussetzenden Demokratiekonzeption bezeichnet Schmitt das Nationalitätsprinzip deshalb als „Grundlage des Völkerrechts“, weil erst nach diesem Prinzip ein „durch politisches Sonderbewußtsein individualisiertes Volk“ einen homogenen Staat bildet und dergestalt seine eigene Identität gegen fremde Einflüsse sichert. Vgl. Schmitt, Verfassungslehre (Fn. 39), S. 231.

41 Vor allem in seinen Werken aus der Postweimarer Zeit stellt Schmitt die Leistungsfähigkeit des Nationalstaates immer wieder in Frage und wendet sich daher gegen den traditionellen, nationalstaatszentrierten Dualismus. Vgl. z. B. C. Schmitt, Über das Verhältnis von Völkerrecht und staatlichem Recht (1940), in: ders., Frieden oder Parzifismus? Arbeiten zum Völkerrecht und zur internationalen Politik 1924-1978, 2005, S. 642 (645): „Ein solcher ausschließlich staatsbezogener Normativismus ist aber nur so lange überzeugend, als der Staatsbegriff des 19. Jahrhunderts und die ihm zugehörige Vorstellung isolierter, in sich geschlossener, eine gewisse Gleichgewichtsordnung aus sich heraus balancierender Staaten unerschüttert ist. Wo aber solche isolierten Gleichheits- und Geschlossenheitsvorstellungen überbrückt und überwölbt sind, wie in jedem Reich, in jedem Bund und in jedem Großraum, ist der Dualismus von Völkerrecht und Landesrecht niemals recht zu Ende denkbar und vor allem niemals restlos ausschließlich. “ Zu seiner Kritik sowohl am Dualismus als auch am Monismus anhand des konkreten Ordnungsdenkens vgl. ferner C. Schmitt, Über die zwei „Dualismen“ des heutigen Rechtssystems (1939), in: ders., Positionen und Begriffe: im Kampf mit Weimar - Genf - Versailles 1923-1939, 3. Aufl. 1994, S. 297 (302 ff.). Aus dieser Perspektive liegt sein Großraumprinzip nahe, welches gegen eine universalistische Ideologie kämpfen soll. Vgl. dazu nur C. Schmitt, Großraum gegen Universalismus (1939), in: ders., Positionen und Begriffe, ebenda, S. 334. 
„Zur Einheit der Nation und zum Bewußtsein dieser Einheit können verschiedene Elemente beitragen: gemeinsame Sprache, gemeinsame geschichtliche Schicksale, Traditionen und Erinnerungen, gemeinsame politische Ziele und Hoffnungen. Die Sprache ist dabei ein sehr wichtiger Faktor, aber nicht für sich allein ausschlaggebend. Maßgebend sind Gemeinsamkeit des geschichtlichen Lebens, bewußter Wille zu dieser Gemeinschaft, große Ereignisse und Ziele. "42

Ohne die Voraussetzung einer identitären homogenen Demokratie hätte das BVerfG die bezeichneten Regelungsgebiete nicht für „demokratisch sensibel“ und daher für „integrationsfest“ erachtet.

Zumindest auf den ersten Blick könnte man hiergegen einwenden, dass der Homogenitätsgedanke im Lissabon-Urteil gar nicht auftaucht, ${ }^{43}$ und zwar deshalb nicht, weil selbst die Qualifizierung der Europäischen Union als „Staatenverbund“ wohl für die offene Staatlichkeit spreche:

„Das Grundgesetz löst sich von einer selbstgenügsamen und selbstherrlichen Vorstellung souveräner Staatlichkeit und kehrt zu einer Sicht auf die Einzelstaatsgewalt zurück, die Souveränität als, völkerrechtlich geordnete und gebundene Freibeit" auffasst. "44

Demzufolge gehe es bei der Feststellung einer integrationsfesten Verfassungsidentität nicht um die Sicherstellung der demokratischen Homogenität, sondern überwiegend um die Gewährleistung der Mitgliedstaaten als „Subjekte demokratischer Legitimation “ ${ }^{45}$ Doch gerade die Verbindung der funktionsfähigen öffentlichen Meinungsbildung mit den „nationalstaatlichen, sprachlichen, historischen und kulturellen Identifikationsmustern " weist deutlich darauf hin, dass erst die nationalstaatlichen, sprachlichen, historischen und kulturellen - kurz: homogenitätsbezogenen - Abgrenzungen eine effektive demokratische Selbstbestimmung ermöglichen würden. ${ }^{46}$ Daraus folgt, dass sich die Zentralstellung der Mitgliedstaaten im Rahmen der europäischen Integration nach Ansicht des BVerfG im Grunde genommen daraus ergeben soll, dass diese die sich nach außen abgrenzende Homogenität zum Ausdruck bringen und genau dadurch zu dem „friedlichen Zusammenwirken der Nationen“ beitragen. Schon deswegen aber soll nicht die gebundene Freiheit der offenen Staaten, sondern in erster Linie vielmehr die Identitätswahrung der einzelnen Mitgliedstaaten

42 Schmitt, Verfassungslehre (Fn. 39), S. 231.

43 So etwa Britz, Vorbehalt (Fn. 22), S. 165.

44 BVerfGE 123, 267 (346).

45 Vgl. BVerfGE 123, 267 (348).

46 Vgl. in diesem Zusammenhang auch Nettesheim, Karlsruher Verkündigung (Fn. 18), S. 117, der in der Begründung des Lissabon-Urteils „eine unglaubliche Ironie“ sieht, dass „das BVerfG seine Vorstellungen von substanzhaltiger Demokratie ausgerechnet am formalsten Element: der Kompetenz zur Teilnahme an der Wahl - festmachen muss.“. 
in den Vordergrund gerückt werden, die, wie dargelegt, eng mit dem Homogenitätsgedanken verbunden ist.

In dem Maße, in dem sich die Lissabon-Entscheidung an einem Schmittschen, $d . h$. die Homogenitätsvorstellungen zugrunde legenden Demokratiebegriff orientiert hat, lässt sich das dargelegte Problem näher beleuchten. Da die vom BVerfG ausgewählten integrationsfesten Regelungsbereiche auf eine die Homogenität voraussetzende Demokratiekonzeption zurückzuführen sind, sprechen sie zwangsläufig für die dualistische Konstruktion der Völkerrechtsordnung, oder richtiger, für den Primat der staatlichen Rechtsordnung nach der Gegenüberstellung von Kelsen. ${ }^{47}$ Auf dieser Grundlage hebt das BVerfG seine Befugnis zur Identitätskontrolle hervor, die dazu führen könnte, „dass Gemeinschafts- oder künftig Unionsrecht in Deutschland für unanwendbar erklärt wird “. ${ }^{48}$ Bereits diese durchaus staatszentrierte Vorstellung würde zu Lasten der Entwicklung europäischer Integration wirken, indem „nach dem Prinzip der begrenzten Einzelermächtigung und unter Achtung der verfassungsrechtlichen Identität " 49 der übergeordnete, bindende Rahmencharakter des Unionsrechts ${ }^{50}$ kaum Berücksichtigung findet. ${ }^{51}$ Vor allem mit der Entwicklung bestimmter integrationsfester und insofern „demokratisch unantastbarer" Sachgebiete würde ggf. die Unvereinbarkeit des deutschen Rechts mit dem Unionsrecht vorschnell als Identitätsverletzung durch das Unionsrecht angesehen, welches daher ohne weiteres für innerstaatlich unanwendbar erachtet würde. Gerade deswegen ist weiterhin zu befürchten, dass die nationalstaatszentrierte Demokratie- und Europarechtstheorie dadurch die individuelle Freiheit beeinträchtigen würde, dass sie im Namen der Demokratie nicht das Einzelindividuum, sondern die politische Einheit bzw. den Staat in den Mittelpunkt stellt. ${ }^{52}$

47 Vgl. dazu näher unten D.

48 Vgl. BVerfGE 123, 267 (354).

49 Vgl. BVerfGE 123, 267 (347).

50 Das Verständnis des Unionsrechts als Rahmen geht auf Kelsens Rahmenvorstellung zurück, wonach die Aktionsfreiheit der rechtsanwendenden Gewalt keineswegs auf deren Ungebundenheit hinweist. Siehe dazu unten D.

51 Zum Anwendungsvorrang des Unionsrechts vgl. insofern nur J. P. Terhechte, Grundwissen - Öffentliches Recht: Der Vorrang des Unionsrechts, JuS 2008, S. 403; R. Arnold, Verfassungsidentität und Letztentscheidungsrecht, in: FS D. Scheuing, 2011, S. 17 (22 f.); S. Griller, Völkerrecht und Landesrecht - unter Berücksichtigung des Europarechts, in: R. Walter/C. Jabloner/K. Zeleny (Hrsg.), Hans Kelsen und das Völkerrecht, 2004, S. 83 (104 ff.). Die Position des BVerfG, die Letzentscheidungsbefugnis zur ultra vires- sowie zur Identitätskontrolle in Anspruch zu nehmen, wird gerade in diesem Zusammenhang vielfach kritisiert. Vgl. dazu etwa Arnold, ebenda, S. 22 f.; Mayer, Europarechtsfreundlichkeit (Fn. 25), S. 252 f., 262; Schwarze, Demokratie (Fn. 18), S. 115 f.; von Bogdandy, Prinzipien (Fn. 15), S. 4.

52 Dazu kritisch auch E.-J. Mestmäcker, Im Schatten des Leviathan. Anmerkungen zum Urteil des BVerfG vom 30.6.2009, in: Hatje/Terhechte (Hrsg.), Grundgesetz (Fn. 18), S. 35 (37, 39). 
Schon Schmitts Demokratietheorie weist deutlich darauf hin, dass bei einer homogenen Demokratie nicht die Freiheit, sondern die (nach innen geltende) Gleichheit der Schlüsselbegriff ist. ${ }^{53}$

\begin{abstract}
„Der demokratische Begriff der Gleichheit ist ein politischer Begriff und nimmt, wie jeder echte politische Begriff, auf die Möglichkeit einer Unterscheidung Bezug. Die politische Demokratie kann daher nicht auf die Unterschiedslosigkeit aller Menschen beruhen, sondern nur auf der Zugehörigkeit zu einem, bestimmten Volk ... Die Gleichheit, die zum Wesen der Demokratie gehört, richtet sich deshalb nur nach innen und nicht nach außen: innerhalb eines demokratischen Staatswesens sind alle Staatsangehörigen gleich. "54
\end{abstract}

Demzufolge stimmt das Mehrheitsprinzip mit der Demokratie nicht deshalb überein, weil es den Willen der Mehrheit zum Ausdruck bringt, sondern vielmehr deshalb, weil „die substanzielle Gleichartigkeit des Volkes so groß ist, dass aus der gleichen Substanz heraus Alle das Gleiche wollen." ${ }^{55}$ In Bezug auf die Völkerrechtsordnung legt Schmitt weiterhin dar, dass der von ihm vertrenene Pluralismus sich eher auf den Pluralismus der verschiedenen Völker als auf den Pluralismus der einzelnen Menschen bezieht. ${ }^{56}$ Dabei liegt das Bedenken nahe, die Freiheit des Einzelnen trotz der grundrechtsschützenden Funktion der Völkerrechtsordnung durch den (homogenen) Willen des Volkes preiszugeben. ${ }^{57}$ Zwar könnte sich das BVerfG von der SchmittLinie schon dadurch unterscheiden, dass es im Lissabon-Urteil eben von der individuellen Freiheit ausgeht und die eigentliche Bedeutung der Demokratie gerade im

53 In diesem Punkt wird der Gegensatz zwischen Schmitt und Kelsen wiederum verschärft. Vgl. dazu nur O. Lepsius, Staatstheorie und Demokratiebegriff in der Weimarer Republik, in: C. Gusy (Hrsg.), Demokratisches Denken in der Weimarer Republik, 2000, S. 366 (408); Lepsius, Demokratietheorie (Fn. 35), S. 78 f.; V. Neumann, Antipoden des Staats- und Völkerrechts: Hans Kelsen und Carl Schmitt, in: M. Gangl (Hrsg.), Die Weimarer Staatsrechtsdebatte, 2011, S. 101 (107f.). Zur Bedeutung individueller Freiheit für die Demokratietheorie Kelsens vgl. unten D.

54 Schmitt, Verfassungslehre (Fn. 39), S. 227. Vgl. ferner C. Schmitt, Vorbemerkung, in: ders., Die geistesgeschichtliche Lage des heutigen Parlamentarismus (1923), 7. Aufl. 1991, S. 13 f.: „Jede wirkliche Demokratie beruht darauf, dass nicht nur Gleiches gleich, sondern, mit unvermeidlicher Konsequenz, das Nicht-gleiche nicht gleich behandelt wird. Zur Demokratie gehört also notwendig erstens Homogenität und zweitens - nötigenfalls - die Ausscheidung oder Vernichtung des Heterogenen.".

55 Schmitt, Verfassungslehre (Fn. 39), S. 229.

56 Vgl. C. Schmitt, Staatsethik und pluralistischer Staat (1930), in: ders., Positionen (Fn. 41), S. 151 (160 f.): „Auch die politische Welt ist wesentlich pluralistisch. Doch sind Träger dieses Pluralismus die politischen Einheiten als solche, d. h. die Staaten.... Die Monarchie ist nach ihrer ideelln Tendenz und Argumentation eher universalistisch, weil sie von Gott sein muß, wenn sie sich nicht demokratisch durch den Willen des Volkes rechtfertigt. Die Demokratie dagegen führt zur Anerkennung jedes der vielen Völker als einer politischen Einheit.... Die Pluralität der Staaten, d. h. der politischen Einheiten der verschiedenen Völker, ist demnach der echte Ausdruck eines richtig verstandenen Pluralismus.".

57 Vgl. in diesem Zusammenhang auch U. Fastenrath, Souveräne Grundgesetzinterpretation - zum Staatsbild des Bundesverfassungsgrichts (Zweiter Senat), in: Giegerich (Hrsg.), Der „offene Verfassungsstaat“ (Fn. 25), S. 295 ff., 309 f. Wie die gemeinschaftliche bzw. mehrheitliche Wertüberzeugung als Darstellung der demokratischen Willensbildung verzerrt wird, zeigt etwa der Inzest-Beschluss des BVerfG (BVerfGE 120, 224). Kritisch zu diesem Aspekt der Inzest-Entscheidung vgl. S.-P. Hwang, Demokratische Willensbildung vor grundrechtlicher Rahmenordnung: Verfassungsrechtliche Überlegungen zur Auseinandersetzung von Gärditz und Zaczyk, Der Staat 51 (2012), S. 233 (242 f.). 
Freiheitsschutz findet. ${ }^{58}$ Doch lässt diese Ansicht außer Acht, dass die Freiheit sich nicht in der Demokratie erschöpfen kann. Mit anderen Worten: Allein die (nationalstaatliche) Demokratie ist nicht in der Lage, die individuelle Freiheit zu garantieren. ${ }^{59}$ So gesehen ist die Stellungnahme des Lissabon-Urteils deshalb zu beanstanden, weil sie trotz oder gerade wegen der Unterstreichung des Freiheits- bzw. Selbstbestimmungsaspekts der Demokratie deren rechtlichen Grenzen gar vernachlässigt, die sich im Rahmen der Europäischen Union nicht lediglich aus dem Verfassungsrecht des eigenen Staates, sondern auch aus dem Unionsrecht ergeben sollen.

\section{Die integrationsfeste Verfassungsidentität im Kampf gegen den normativen Universalismus: Zur Abkehr vom Kelsenschen Demokratiebegriff durch das Lissabon-Urteil}

Dem Vorhergehenden ist zu entnehmen, dass der Demokratiebegriff der LissabonEntscheidung in erster Linie durch dessen Verknüpfung mit der staatlichen Souveränität gekennzeichnet ist. ${ }^{60}$ Trotz der Aussage der Europarechtsfreundlichkeit steht das BVerfG der europäischen Integration entgegen, ${ }^{61}$ indem es an der nationalstaatszentrierten, von Homogenität geprägten Demokratievorstellung festhält. Auf dieser Grundlage wird verständlich, weswegen das BVerfG das demokratische Fundament der Europäischen Union einerseits in Frage stellt, andererseits aber bald wieder rechtfertigt: Gemessen an „staatlichen Demokratieanforderungen“ fehle es der Europäischen Union an „einem durch gleiche Wahl aller Unionsbürger zustande gekommenen politischen Entscheidungsorgan mit der Fähigkeit zur einheitlichen Repräsentation des Volkswillens“. Das Europäische Parlament sei daher „kein Repräsentationsorgan eines souveränen europäischen Volkes. “62 Trotz diesem Demokratiedefizit entspreche die Europäische Union demokratischen Grundsätzen, weil „sie

58 Vgl. nur BVerfGE 123, 267 (346): „Souveräne Staatlichkeit steht danach für einen befriedeten Raum und die darin gewährleistete Ordnung auf der Grundlage individueller Freiheit und kollektiver Selbstbestimmung. Der Staat ist weder Mythos noch Selbstzweck, sondern die historisch gewachsene, global anerkannte Organisationsform einer handlungsfähigen politischen Gemeinschaft.".

59 Daher kann gegen die vorstehende Betrachtung auch nicht eingewandt werden, selbst der (im LissabonUrteil verkörperte) Etatismus sei nicht Gegner, sondern Voraussetzung der Freiheit. Dieser Aussage liegt wiederum das Vorverständnis zugrunde, erst und gerade die nationalstaatliche Demokratie ermögliche die Freiheitsverwirklichung. Bereits diese Voraussetzung distanziert sich aber grundlegend von einer liberal-pluralistischen Freiheits- und Demokratievorstellung. Vgl. dazu näher unten bis .

60 Vgl. auch J. P. Terhechte, Europäischer Bundesstaat, supranationale Gemeinschaft oder Vertragsunion souveräner Staaten? - Zum Verhältnis von Staat und Union nach dem Lissabon-Urteil des BVerfG, in: Hatje/Terhechte (Hrsg.), Grundgesetz (Fn. 18), S. 135 (139f., 145 f.); von Bogdandy, Prinzipien (Fn. 15), S. 2 ff.; Thym, Integration (Fn. 22), S. 565; Murkens, Identity (Fn. 26), S. 527; D. Grimm, Das Grundgesetz als Riegel vor einer Verstaatlichung der Europäischen Union. Zum Lissabon-Urteil des Bundesverfassungsgerichts, Der Staat 48 (2009), S. 475 (481, 486, 490); D. Halberstam/C. Möllers, The German Constitutional Court says „Ja zu Deutschland!“, 10 German L.J. 1241 (2009), S. 1247.

61 Vgl. in diesem Zusammenhang nur Schönberger, Europäische Union (Fn. 18), S. 557, wo ausdrücklich kritisiert wurde, dass „das BVerfG die europäische Integration nicht mehr mitgestalten, sondern sie allenfalls behindern will“.

62 Vgl. BVerfGE 123, 267 (372). 
bei qualitativer Betrachtung ihrer Aufgaben- und Herrschaftsorganisation gerade nicht staatsanalog aufgebaut ist ". ${ }^{63}$ Genau deshalb aber dürfe die Entwicklung europäischer Integration nicht dem „Prinzip der begrenzten Einzelermächtigung“ zuwider laufen, denn „,eine Verstärkung der Integration kann verfassungswidrig sein, wenn das demokratische Legitimationsniveau mit dem Umfang und dem Gewicht supranationaler Herrschaftsmacht nicht Schritt hält" 64

„Das Prinzip der begrenzten Einzelermächtigung ist ein Schutzmechanismus zur Erhaltung mitgliedstaatlicher Verantwortung. Die Europäische Union ist nur insoweit für einen Sachverhalt zuständig, wie sie diese Zuständigkeit von den Mitgliedstaaten übertragen bekommen hat. Die Mitgliedstaaten sind danach verfasster politischer Primärraum ihrer jeweiligen Gemeinwesen, die Europäische Union trägt sekundäre, das heißt delegierte Verantwortung für die ibr übertragenen Aufgaben. "65

Es liegt auf der Hand, dass das Lissabon-Urteil die Möglichkeit einer „Staatwerdung “ der Europäischen Union und daher einer Demokratisierung der Europäischen Union deshalb ausschließt, weil nach ihm die nationalstaatliche, souveränitätszentrierte, die politische Einheit der Mitgliedstaaten zum Ausdruck bringende Demokratie nach wie vor im Mittelpunkt stehen muss. Dies spricht wiederum dafür, dass die Homogenitätsbedingungen für eine lebendige und funktionsfähige Demokratie unentbehrlich sind. Genau auf dieser Erkenntnisgrundlage stellt das BVerfG ohne weiteres fest, die Europäische Union sei - angesichts des Fehlens eines europäischen Volkes ${ }^{66}$ - keineswegs in der Lage, eine funktionsfähige öffentliche Meinungsbildung zu ermöglichen. ${ }^{67}$

So gesehen verwundert es nicht, dass das Lissabon-Urteil im Vergleich zur Maastricht-Entscheidung als „eine bemerkenswerte Kehrtwende“ bezeichnet wird:

„Einerseits identifiziert das BVerfG zutreffend das strukturelle Demokratiedefizit als zentrale verfassungsrechtliche und politische Herausforderung. Doch anstatt einer vorsichtigen Unterstützung konventioneller Gegenmaßnabmen

63 Vgl. BVerfGE 123, 267 (371). (Hervorhebung durch Verf.).

64 Vgl. BVerfGE 123, 267 (364).

65 Vgl. BVerfGE 123, 267 (381f.).

$66 \mathrm{Zu}$ diesem Aspekt des Lissabon-Urteils vgl. auch A. Hatje, Demokratische Kosten souveräner Staatlichkeit im europäischen Verfassungsverbund - zu den Perspektiven der Demokratie in der Europäischen Union nach dem Urteil des Bundesverfassungsgerichts zum Vertrag von Lissabon, in: Hatje/ Terhechte (Hrsg.), Grundgesetz (Fn. 18), S. 123 (128).

67 Zur Verteidigung dieser Stellungnahme des BVerfG vgl. aber Britz, Vorbehalt (Fn. 22), S. 166: „Zwar geht es auch hier noch um Identifikation, die aber gerade nicht als kollektiver Vergemeinschaftungsvorgang beschrieben wird, sondern als Vielzahl individueller Vorgänge der Wahrnehmung des Öffentlichen begriffen werden kann. Das Demokratiedefizit der EU wird nicht auf die Volks-Untauglichkeit der Europäer, sondern auf das Fehlen einer funktionsfähigen öffentlichen Meinung zurückgeführt.“. 
auf europäischer Ebene, insbesondere mit Blick auf das Europäische Parlament, präsentiert das Gericht entsprechende Reformen als Gefährdung der souveränen Staatlichkeit, weil die Errichtung einer demokratischen Infrastruktur die Kontrolle der EU-Rechtsetzung durch die Mitgliedstaaten untergräbt." 68

Hingegen vermag die Meinung, im Gegensatz zum Maastricht-Urteil sei im LissabonUrteil die Souveränitätsdebatte „gewissermaßen an die Stelle der früheren Volksdebatte getreten “, ${ }^{69}$ nicht zu überzeugen. Sie vernachlässigt vor allem die Homogenitätsvoraussetzungen des BVerfG bei der Hervorhebung „des Staates und seiner Souveränität ${ }^{\text {"70 }}$ und kann infolgedessen nicht erklären, warum gerade die identitätsrelevanten Regelungsgegenstände als demokratisch besonders sensible und daher integrationsfeste Sachbereiche qualifiziert werden müssten.

Vor diesem Hintergrund liegt die Kritik von Kelsen nahe. Im Gegensatz zur bisherigen herrschenden Souveränitätsvorstellung führt Kelsen aus:

„Das Dogma der Staatssouveränität mit dem daraus resultierenden Primat der eigenstaatlichen Rechtsordnung entspricht durchaus jener subjektivistischen, in ibrer letzten Konsequenz dem Solipsismus verfallenden Anschauung, die das Einzelindividuum, d. h. aber das Ich als Zentrum der Welt und diese daher nur als Wille und Vorstellung des Ich begreifen will. Es ist ein radikaler StaatsSubjektivismus, dem der Primat der Völkerrechtsordnung als Ausdruck einer spezifisch objektivistischen Welt- und Rechts-Anschaunng gegenübertritt. "71

Bereits diese Aussage macht klar, dass Kelsen sich nicht nur gegen die klassische dualistische Konstruktion der Völkerrechtsordnung wendet, sondern darüber hinaus gegen diejenige monistische Konstruktion, die vom Primat der eigenstaatlichen

68 Thym, Integration (Fn. 22), S. 576 f. Ähnlich Nettesheim, Karlsruher Verkündigung (Fn. 18), S. 118 f.; Schönberger, Europäische Union (Fn. 18), S. 551 f.; G. Nicolaysen, Das Lissabon-Urteil des Bundesverfassungsgerichts im Kontext der Europarechtsprechung des Bundesverfassungsgerichts, in: Hatje/ Terhechte (Hrsg.), Grundgesetz (Fn. 18), S. 9 (30). Zu schärferer Kritik vgl. Murkens, Identity (Fn. 26), S. $526 \mathrm{f} .:$,so long as Germany is a state, the European Union cannot become a state.“.

69 So Britz, Vorbehalt (Fn. 22), S. 165.

70 Vgl. Britz, Vorbehalt (Fn. 22), S. 165 („Insgesamt ist vom Volk im Lissabon-Urteil nicht viel die Rede. Im Vordergrund stehen vielmehr zunächst das Individuum [...] und dann vor allem der Staat und seine Souveränität.").

71 Kelsen, Reine Rechtslehre (Fn. 36), S. 150. Vgl. dazu ferner Kelsen, Principles (Fn. 36), S. 581 ff., 585 f.; H. Kelsen, Die Einheit von Völkerrecht und staatlichem Recht, ZaöRV 19 (1958), S. 234 (246 ff.). 
Rechtsordnung ausgeht. ${ }^{72}$ Denn die beiden nationalstaatszentrierten Vorstellungen stehen zwangsläufig der Vielheit gleichgeordneter Staaten bzw. einer pluralistischen Begründung der europäischen Integration entgegen, indem die identitätswahrende Funktion der demokratischen Willensbildung immer wieder in den Vordergrund gerückt wird.

„So bedeutet der Primat der einzelstaatlichen Rechtsordnung letzten Endes nicht nur die Leugnung der Souveränität aller anderen Staaten und damit deren rechtlicher Existenz als Staaten im Sinne des Souveränitätsdogmas, sondern auch die Lengnung des Völkerrechts. " 73

Offenbar lässt sich das Lissabon-Urteil keineswegs durch dessen Leugnung des Unionsrechts sowie der Souveränität anderer Mitgliedstaaten der Europäischen Union kennzeichnen. Doch hebt es die Notwendigkeit einer Abgrenzung demokratisch sensibler Regelungsbereiche von der europäischen Integration deshalb hervor, weil nach Ansicht des BVerfG besonders in diesen Bereichen die Elemente demokratischer Selbstbestimmung nicht durch die Europäisierung geschwächt werden dürfen. Genau in diesem Punkt aber kommt die Vorstellung eines Staats-Subjektivismus zum Ausdruck, denn das BVerfG geht ausdrücklich davon aus, die Überschreitung der Grenzen sachbereichsbezogener integrationsfester Verfassungsidentität würde zum Souveränitäts- bzw. Demokratieverlust führen. ${ }^{74}$ Gerade unter dieser Voraussetzung sei die Stellung des Bundestags zu unterstreichen, da erst dieser den eigenen Volkswillen wahrnehmen und dergestalt eine echte demokratische Entscheidung treffen könne. Bereits dieser Annahme wohnt das nationalstaatszentrierte Souveränitäts- und Demokratieverständnis inne, wonach die in kultureller, historischer und sprachlicher Hinsicht besonders sensiblen Entscheidungen nicht nach dem Willen eines Anderen, sondern nur nach dem Willen des Ich getroffen werden dürfen. Das BVerfG legt explizit dar:

„Das Grundgesetz erstrebt die Einfügung Deutschlands in die Rechtsgemeinschaft friedlicher und freiheitlicher Staaten. Es verzichtet aber nicht auf die in dem letzten Wort der deutschen Verfassung liegende Souveränität als Recht

72 Während in seinen früheren Werken die (vor allem von Heinrich Triepel vertretene) dualistische Konstruktion der Völkerrechtsordnung Hauptgegenstand der Kritik ist (vgl. dazu insbesondere Kelsen, Problem (Fn. 36), S. 120 ff.), hebt Kelsen später die „monistische Natur“ des herrschenden Dualismus stärker hervor und bemüht sich folglich um die Gegenüberstellung zwischen „den beiden monistischen Konstruktionen “, nämlich dem Primat der staatlichen Rechtsordnung einerseits und dem Primat der Völkerrechtsordnung andererseits. Vgl. z. B. Kelsen, Reine Rechtslehre, 2. Aufl. (Fn. 37), S. 333 ff., 339 ff.; Kelsen, Einheit (Fn. 71), S. 235 ff.; Kelsen, Principles (Fn. 36), S. 573 ff.; im Ansatz schon Kelsen, Problem (Fn. 36), S. 151.

73 Kelsen, Reine Rechtslehre (Fn. 36), S. 151.

74 Vgl. auch Nettesheim, Karlsruher Verkündigung (Fn. 18), S. 114 („In den Äußerungen des Gerichts schwingt zudem ein solipsistisches Verständnis von Identität mit [...].“). 
eines Volkes, über die grundlegenden Fragen der eigenen Identität konstitutiv $z u$ entscheiden. "75

Demzufolge lässt sich eine antipluralistische Orientierung des Europarechts aber nicht vermeiden, indem die Staatssouveränität auf einer subjektivistischen Erkenntnisgrundlage immer wieder als nicht einschränkbare, „höchste Rechtsautorität“ begriffen wird. ${ }^{76}$ Wie Kelsen mit Recht betrachtet, dient der Staats-Subjektivismus zwangsläufig zur Rechtfertigung einer Politik, die „jede weitgehende Einschränkung der Aktionsfreiheit des Staats ablehnt“ und insoweit für die „Ideologie des mit dem Dogma der Staatssouveränität operierenden Imperialismus " spricht. ${ }^{77}$

So gesehen widerspricht die nationalstaatszentrierte Vorstellung des BVerfG nicht nur dem Kelsenschen normativen Universalismus. Vielmehr läuft sie der den Pluralismus zugrunde legenden europäischen Rechtsordnung ${ }^{78}$ zuwider und würde sich daher zu Lasten der Weiterentwicklung der europäischen Integration wirken. Auch wenn das Lissabon-Urteil die grundrechtlichen Aspekte der demokratischen Selbstbestimmung wiederholt betont, tritt nach dem staats-subjektivistischen Demokratieverständnis des BVerfG das Individuum zwangsläufig in den Hintergrund, indem die Gegenüberstellung von der eigenen und der europäischen Rechtsordnung auf die Identitätswahrung der eigenen Gemeinschaft und infolgedessen auf die maßgebliche Rolle der herrschenden bzw. mehrheitlichen Wertvorstellungen der eigenen Gemeinschaft hinweist. ${ }^{79}$ In Bezug auf die Strafrechtspflege betont das BVerfG etwa:

„Die demokratische Selbstbestimmung ist ... in einer besonders empfindlichen Weise berührt, wenn eine Rechtsgemeinschaft gehindert wird, über die Strafbarkeit von Verhaltensweisen und gar die Verhängung von Freiheitsstrafen nach Maßgabe eigener Wertvorstellungen zu entscheiden. Das gilt umso mehr, je enger diese Wertvorstellungen mit historischen Erfabrungen, Glaubenstraditionen und anderen für das Selbstgefühl der Menschen und ibrer Gemeinschaft wesentlichen Faktoren verknüpft sind. "80

Selbst diese Ausführung deutet darauf hin, dass die Demokratiekonzeption des BVerfG nicht mit der universellen Freiheitsgewährleistung des Einzelnen, sondern

75 BVerfGE 123, 267 (400).

76 Vgl. Kelsen, Reine Rechtslehre, 2. Aufl. (Fn. 37), S. 342: „Die Souveränität des Staates - die der Primat des Völkerrechts völlig ausschließt - ist etwas ganz anderes als die Souveränität des Staates, die durch das Völkerrecht eingeschränkt wird. Jene bedeutet: höchste Rechtsautorität; diese: Aktionsfreiheit des Staates.".

77 Vgl. Kelsen, Reine Rechtslehre, 2. Aufl. (Fn. 37), S. 345.

78 Zur pluralistischen Grundlage der europäischen Integration vgl. auch Murkens, Identity (Fn. 26), S. 531; Mestmäcker, Schatten (Fn. 52), S. 42 f.; van Ooyen, Staatsvolk (Fn. 26), S. 59 f.

79 Hingegen stellt sich bei Kelsen das Individuum immer wieder als Subjekt des Völkerrechts dar. Vgl. z. B. Kelsen, Problem (Fn. 36), S. 126 ff.; Kelsen, Reine Rechtslehre, 2. Aufl. (Fn. 37), S. 325-328; Kelsen, Principles (Fn. 36), S. 180 ff., $221 \mathrm{ff}$.

80 BVerfGE 123, 267 (412). 
mit der homogenitätsbezogenen Identitätsgewährleistung der eigenen Gemeinschaft verbunden ist, wobei wohl die Mehrheitsherrschaft, nicht aber das Kelsensche, d. h. den Minderheitenschutz voraussetzende Mehrheitsprinzip ${ }^{81}$ eine Rolle spielt.

So betrachtet liegt es nahe, dass die Zentralstellung des (nationalen) Parlaments im Lichte der Lissabon-Entscheidung einerseits und im Rahmen der Kelsenschen Demokratietheorie andererseits aus völlig unterschiedlichen Überlegungen erfolgt: Während diese von der individuellen Freiheit ausgeht und deshalb für die parlamentarische Demokratie plädiert, weil diese durch eine Kompromissgestaltung ${ }^{82}$ zur optimalen Freiheitsverwirklichung beiträgt, neigt jene dazu, die Willensbildung des Parlaments mit der Wahrnehmung eigener Wertvorstellungen gleichzusetzen. Aus dieser Perspektive wird deutlich, wie sich das homogenitätsorientierte Demokratieverständnis des BVerfG in der Lissabon-Entscheidung von der Kelsenschen pluralistischen Demokratie unterscheidet. Im Gegensatz zur Demokratietheorie Kelsens, wonach die normative Kontrolle der parlamentarischen Entscheidung sich darauf richten soll, die Freiheit des Einzelnen vor der Willkür der Majorität zu schützen, ${ }^{83}$ verweist die Demokratiekonzeption des Lissabon-Urteils auf die Integrationsverantwortung des Parlaments, die

„ihren verfassungsrechtlichen Gehalt anhand begrifflich abgegrenzter Wesenbeiten der staatlichen Demokratie und ibrer Souveränität, des europarechtlichen Verbundes und der Nicht-Souveränität der EU [gewinnt]. "84

Daraus folgt, dass das BVerfG im Außenverhältnis das nationale Parlament überwiegend als souveräne Instanz bezeichnet, während Kelsen in seiner Völkerrechtstheorie die staatliche Souveränität erheblich relativiert und insofern nicht die nationalstaatlichen Selbstbestimmungsaspekte, sondern die universalistische, relativistische Perspektive der Demokratie vor Augen führt. ${ }^{85}$

81 Vgl. nur Kelsen, Demokratie (Fn. 35), S. 55 ff., 101.

82 Vgl. Kelsen, Demokratie (Fn. 35), S. 57 f., wonach das parlamentarische Verfahren „auf die Erzielung eines Kompromisses“ gerichtet sei.

83 Vgl. Kelsen, Demokratie (Fn. 35), S. 75 f. Zu einer näheren Analyse vgl. Hwang, Rechtsanwendung (Fn. 35), S. 454 ff. Zur Freiheitssicherung auf europäischer Ebene vgl. ferner Mestmäcker, Schatten (Fn. 52), S. 43; Ruffert, Grenzen (Fn. 18), S. 1207.

84 So Mestmäcker, Schatten (Fn. 52), S. 38. Vgl. insofern auch M. Niedobitek, Die Integrationsverantwortung von Bundestag und Bundesrat nach dem Lissabon-Urteil des Bundesverfassungsgerichts, in: G. Abels/A. Eppler (Hrsg.), Auf dem Weg zum Mehrebenenparlamentarismus?, 2011, S. 159 (169), wo behauptet wird, im Lissabon-Urteil werde der Begriff der Integrationsverantwortung „im Kontext von Begriffen wie ,Grenzfälle‘ bzw. ,Grenzüberschreitungen“ “ verwendet.

85 So deutlich bei Kelsen, Reine Rechtslehre (Fn. 36), S. 158 ff., 160 („Die Reine Rechtslehre relativiert den Staat. Sie erkennt ihn als rechtliche Zwischenstufe und gewinnt so die Einsicht: dass von der alle Staaten umfassenden universalen Völkerrechtsgemeinschaft zu den dem Staat eingegliederten Rechtsgemeinschaften eine kontinuierliche Abfolge allmählich ineinander übergehender Rechtsgebilde führt.“). Vgl. auch Ehs, Einführung (Fn. 26), S. 15 ff. 
Genau durch diesen Gegensatz veranschaulicht sich, dass das BVerfG eigentlich die „Identifikation der Staatsbürger mit ihrem Staat" ${ }^{\text {86 }}$ suggeriert, ${ }^{87}$ wobei die Heterogenität zwischen den Individuen und folglich die individuelle Freiheit kaum noch in Betracht kommt: „Wo das souveräne Selbstbestimmungsrecht des Staates dem Selbstbestimmungsrecht der Bürger entsprechen soll, geraten die Freiheitsrechte der Bürger aus dem Blick. “ 88 Gerade deswegen aber müsste die Position des BVerfG dem von Kelsen vertretenen freiheitlichen (Wert-)Relativismus widersprechen, indem sie sich aufgrund des Homogenitätsgedankens wohl an dem Staats-Subjektivismus orientiert, der besonders im Rahmen internationaler Menschenrechtsordnung dem antiuniversalistischen Kulturrelativismus ${ }^{89}$ nicht fern liegt. Hier zeigt sich wiederum, wie sich die Schmittsche homogenitätsgeprägte Völkerrechtslehre als Kontrastschablone zu Kelsens Pluralismus und Universalismus in der Demokratiekonzeption der Lissabon-Entscheidung widergespiegelt hat.

Aus Sicht von Kelsen also ist das nationalstaatszentrierte Verständnis des BVerfG sowohl für das Prinzip der begrenzten Einzelermächtigung ${ }^{90}$ als auch für das Subsidiaritätsprinzip ${ }^{91}$ durchaus fragwürdig. Zwar werden beide Grundsätze im Rahmen des Unionsrechts ausdrücklich anerkannt. Allerdings spricht dies nichts dafür, einen sachlich unantastbaren und integrationsfesten Kerngehalt der demokratischen Selbstbestimmung zu begründen. Denn: Aus der Perspektive einer pluralistischen Demokratie steht zur Freiheitssicherung weder die Staatssouveränität noch die (von Homogenität geprägte) Gemeinschaft, sondern nach wie vor das Einzelindividuum im Mittelpunkt. Daraus folgt, dass die den EU-Mitgliedstaaten eingeräumte Akti-

86 Vgl. Mestmäcker, Schatten (Fn. 52), S. 39.

87 Dies bestätigt sich schon dadurch, dass das BVerfG nach außen die Handlungsfreiheit nicht des Einzelnen, sondern „des selbstbestimmten Volkes“ betont. Vgl. dazu BVerfGE 123, 267 (350).

88 Mestmäcker, Schatten (Fn. 52), S. 39.

89 Der anti-universalietische Charakter des Kulturrelativismus zeigt sich dadurch, dass dieser überwiegend für die Wahrung der (unantastbaren) Staatssouveränität spricht und sich gerade in diesem Sinne gegen die Entfaltung der universalen Völkerrechtsordnung wendet. Vgl. in diesem Zusammenhang auch Kelsen, Principles (Fn. 36), S. 581: „[T] he real purpose of the pluralistic doctrine is not so much to assert the mutual independence of national and international law but rather to maintain the idea that national law, and that means a definite national legal order is not subordinated to international law and hence may be considered to be the supreme legal authority. "Zum Kulturrelativismus im Lichte der europäischen Menschenrechtsordnung vgl. ferner E. Brems, The Margin of Appreciation Doctrine in the Case-Law of the European Court of Human Rights, ZaöRV 1996, S. 240 (307 ff.); J. Gerards, Pluralism, Deference and the Margin of Appreciation, European Law Journal 2011, S. 80 (104f.).

90 Vgl. nur BVerfGE 123, 267 (350), wo das Prinzip der begrenzten Einzelermächtigung als „vertraglichen Ausdruck der staatsverfassungsrechtlichen Grundlegung der Unionsgewalt" verstanden wird. Vgl. dazu kritisch auch P.-C. Müller-Graff, Das Karlsruher Lissabon-Urteil: Bedingungen, Grenzen, Orakel und integrative Optionen, integration 2009, S. 331 (347f.).

91 Beim Subsidiaritätsprinzip hält das Lissabon-Urteil überwiegend daran fest, dass „die auf europäischer Ebene bestehenden Einzelermächtigungen in einer die mitgliedstaatlichen Zuständigkeiten schonenden Weise wahrgenommen werden “. BVerfGE 123, 267 (383). Vgl. in diesem Zusammenhang auch von Bogdandy, Prinzipien (Fn. 15), S. 4 f., der von der „übermäßigen Betonung des Subsidiaritätsprinzips“ spricht. Hingegen sieht Britz, Vorbehalt (Fn. 22), S. 163, in der Meinung des BVerfG aber doch ein „demokratisches Fundament“. 
onsfreiheit ${ }^{92}$ schon von Freiheitswegen nicht uneingeschränkt sein kann. Vielmehr dient auch und gerade diese Aktionsfreiheit zur Freiheitsverwirklichung im europäischen Raum und müsste schon deswegen an die Vorgaben der europäischen Rechtsordnung gebunden werden..$^{93}$

Mit anderen Worten: Nach der pluralistischen Demokratiekonzeption werden die Identifikation der Staatsbürger mit ihrem Staat sowie die Homogenität zwischen den Staatsbürgern nicht mehr ohne weiteres vorausgesetzt. Daher droht auch durch eine weitreichende europäische Integration kein Souveränitäts- bzw. Demokratieverlust, wenn die europäische Rechtsordnung auf die individuelle Freiheitsverwirklichung ausgerichtet ist und in diesem Sinne ihre Bindungskraft entfaltet.

Demzufolge steht fest, dass weder das Prinzip der begrenzten Einzelermächtigung noch das Subsidiaritätsprinzip dahin missverstanden werden darf, dass die Geltungskraft des Unionsrechts zur Erhaltung demokratischer Selbstbestimmung der Mitgliedstaaten möglichst zurückhaltend ausgelegt werden müsste. Denn selbst die Demokratie verweist weder auf die Maximierung souveräner Selbstbestimmung noch auf die integrationsfeste Identität, sondern vielmehr auf die Integrationsfähigkeit der von den Mitgliedstaaten konsentierten Zielsetzung einer umfassenden Freiheitsgewährleistung, ${ }^{94}$ die auf der Grundlage von Pluralismus und Relativismus mit dem Konzept des Minderheitenschutzes in Einklang steht.

\section{E. Demokratie und europäische Integration aus Sicht der Demokratie- und Völkerrechtstheorie Kelsens}

Aus dem Gesagten ergibt sich, dass - aus der Perspektive der Demokratie- und Völkerrechtstheorie Kelsens - die europäische Integration keinen Gegensatz zur demokratischen Selbstbestimmung aufweist.

Einerseits ist festzustellen, dass die europäische Integration zwar zur Relativierung der souveränen Staatlichkeit, nicht aber zur Leugnung der demokratischen Selbstbestimmung der Mitgliedstaaten führt. Dies zeigt sich vor allem dadurch, dass in der europäischen Rechtsgemeinschaft die Rahmenordnung des Unionsrechts die Mit-

92 Terminologisch vgl. Kelsen, Reine Rechtslehre, 2. Aufl. (Fn. 37), S. 342 (vgl. auch oben Fn. 76).

93 Zur normlogischen Bindung der staatlichen Aktionsfreiheit an die Völkerrechtsordnung Kelsen, Reine Rechtslehre (Fn. 36), S. 158 ff.; Kelsen, Reine Rechtslehre, 2. Aufl. (1960) (Fn. 37), S. 342 f. Zur Bindungswirkung des Unionsrechts aus freiheitlicher Perspektive vgl. ferner Murkens, Identity (Fn. 26), S. 531; J. Busch/T. Ehs, Nachwort: EUropa als Rechtsgemeinschaft, in: Ehs (Hrsg.), Hans Kelsen (Fn. 26), S. 95 (104 ff.); Mestmäcker, Schatten (Fn. 52), S. 43; Ruffert, Grenzen (Fn. 18), S. 1207.

94 Dies zeigt sich schon durch die herausragende Bedeutung der EMRK für die Entwicklung der europäischen Rechtsordnung. Vgl. dazu nur Herdegen, Europarecht (Fn. 18), S. 11 ff.; R. Bernhardt, Europäische Menschenrechtskonvention: Entwicklung und gegenwärtiger Stand, in: D. Merten/H.-J. Papier (Hrsg.), Handbuch der Grundrechte in Deutschland und Europa, Bd. /1, 2010, $\mathbb{} 137$. 
gliedstaaten gerade zur Verwirklichung von Rechtsstaatlichkeit und Demokratie ermächtigt und zugleich verpflichtet. ${ }^{95}$

Andererseits kann die demokratische Willensbildung nicht zur Rechtfertigung jeder beliebigen, ungebundenen Entscheidung dienen. Vielmehr muss die Demokratie normativen Kontrollen unterliegen, um ihre Funktionsfähigkeit aufrechtzuerhalten. Denn: Wenn die Demokratie sich durch die stetige gegenseitige Beeinflussung von Majorität und Minorität auszeichnet, so ist diese als Opposition „nicht nur begrifflich [vorauszusetzen], sondern auch politisch [anzuerkennen] und in den Grund- und Freiheitsrechten, im Prinzipe der Proportionalität [zu schützen] “. ${ }^{96}$ Daraus folgt, dass vor allem die Zweckbestimmung des Minderheitenschutzes der demokratischen Willensbildung normative Grenzen ziehen soll. Daher legt Kelsen mit Nachdruck dar:

„An einer systematischen Ausgestaltung aller Kontrollinstitutionen hängt in hohem Maße das Schicksal der modernen Demokratie. Demokratie ohne Kontrolle ist auf die Dauer unmöglich. Denn das Freilassen jener Selbstbeschränkung, die das Prinzip der Legalität darstellt, bedeutet die Selbstauflösung der Demokratie." 97

Aus dieser Perspektive liegt es nahe, dass die mit dem Vorrang des Unionsrechts verbundene Relativierung der staatszentrierten Souveränität der Demokratie nicht widerspricht. Vielmehr trägt dieser Vorrang umgekehrt zur Demokratieverankerung der europäischen Rechtsgemeinschaft bei, indem das Unionsrecht genau im Streben nach Freiheitsverwirklichung auch zum Minderheitenschutz dient. ${ }^{98}$

Die Kelsensche Lehre weist ferner und grundlegender darauf hin, dass die demokratische Selbstbestimmung die Homogenität zwischen den Bürgern weder voraussetzt noch garantiert. Mit anderen Worten: Die Kelsensche monistische Vorstellung der europäischen Rechtsgemeinschaft ist im Grunde genommen auf das pluralistische Demokratieverständnis zurückzuführen. Nach Ansicht von Kelsen geht die Demo-

95 Aus der Kelsenschen Perspektive ist also festzustellen, dass das Subsidiaritätsprinzip nicht mit der prinzipiellen Zurückhaltung der Europäischen Union, sondern vielmehr mit dem Rahmencharakter des Unionsrechts zusammenhängt, womit die Bindungskraft des Unionsrechts sich genau durch dessen ermächtigende Rahmensetzung entfaltet. Zum Bindungscharakter des Rahmens von ermächtigenden Normen höherer Stufe aus Sicht von Kelsen vgl. näher S.-P. Hwang, Rechtsbindung durch Rechtsermächtigung: Ein topisches Verständnis der Reinen Rechtslehre zur Erläuterung des Verhältnisses von Richterbindung und Richterfreiheit, Rechtstheorie 40 (2009), S. 43 (52 ff.).

96 Kelsen, Demokratie (Fn. 35), S. $101 \mathrm{f}$.

97 Kelsen, Demokratie (Fn. 35), S. 76. Vgl. in diesem Zusammenhang auch Kelsen, Staatsform (Fn. 38), S. 49.

98 Vgl. insofern auch Zürn, Bundesverfassungsgericht (Fn. 32), S. 52. 
kratie nicht von den Homogenitätsbedingungen aus. ${ }^{99}$ Häufig beweist die Realität vielmehr, dass eine demokratische Ordnung als kompromissgestaltender „Ruhepunkt " 100 besonders dort notwendig ist, wo Heterogenität in der Gesellschaft herrscht. ${ }^{101}$

In diesem Zusammenhang veranschaulicht sich, dass die Bindung der demokratischen Willensbildung der Mitgliedstaaten an die Rahmenordnung des Unionsrechts deshalb unentbehrlich ist, weil sie durch die Eingliederung der mitgliedstaatlichen demokratischen Selbstbestimmung in die europäische Rechtsgemeinschaft zur Erzielung eines Kompromisses zwischen Majorität und Minorität im Europaraum beiträgt. So gesehen vermag die These des Lissabon-Urteils, erst in der innerstaatlichen Demokratie lasse sich eine funktionsfähige öffentliche Meinungsbildung völlig realisieren, nicht zu überzeugen. Denn der Funktionsfähigkeit der öffentlichen Meinung liegt nicht die Homogenitätsbedingung zugrunde, sondern vielmehr die Funktionsfähigkeit des Interessenausgleichs zwischen Majorität und Minorität, d. h. zwischen heterogenen Gesichtspunkten.

Dem Vorhergehenden ist zu entnehmen, dass zwischen der Völkerrechtslehre und der Demokratietheorie Kelsens eine enge Beziehung besteht. Nach Ansicht von Kelsen ist die souveräne Staatlichkeit nicht nur aus normlogischer, sondern darüber hinaus auch aus demokratischer Sicht durch eine monistische Konstruktion der supranationalen Rechtsordnung zu relativieren, weil nur so eine pluralistische, d. h. freiheitssichernde Demokratie zu erwarten ist, wobei weder eine gemeinschaftliche bzw. mehrheitliche Wertvorstellung noch die nationalstaatliche, identitätsbewusste Selbstbestimmung, sondern nach wie vor die Freiheitsgarantie für den Einzelnen und daher der Schutz der Minorität vor der Willkür der Majorität die Zentralrolle spielt. Auch Kelsen selbst stellt den demokratischen Zusammenhang seiner Völkerrechtstheorie ausdrücklich dar:

99 Die Aussage von Kelsen: „Majorität und Minorität müssen sich miteinander verständigen können, wenn sie sich miteinander vertragen wollen. Die tatsächlichen Voraussetzungen für die gegenseitige Verständigung der an der sozialen Willensbildung Beteiligten müssen also gegeben sein: eine kulturell relativ homogene Gesellschaft, insbesondere gleiche Sprache“ (Kelsen, Demokratie (Fn. 35), S. 65 f.), lässt sich also nicht dahin (miss)verstehen, dass auch Kelsen Homogenität als Bedingung für eine funktionsfähige Demokratie anerkenne (so aber Neumann, Antipoden (Fn. 53), S. 108 f.). Vielmehr weist Kelsen hier lediglich darauf hin, dass die relative Homogenität bzw. die gleiche Sprache zu einer verständlichen Kommunikation zwischen Mehrheit und Minderheit beitragen würde. Dies besagt aber keineswegs, dass ohne Homogenitätsbedingungen eine Kompromissgestaltung unmöglich wäre. Wichtig ist vielmehr, dass das Minderheiteninteresse nicht wegen Kommunikationsschwierigkeiten preisgegeben werden darf. Genau in diesem Zusammenhang betont Kelsen, dass „bei übernationalen, internationalen Gemeinschaften, speziell in national gemischten, sog. Nationalitätsstaaten, die Entscheidung der nationalen Kulturfragen dem Zentralparlament entzogen und der Autonomie, d. h. den Vertretungskörpern der nach dem Personalitätsprinzip organisierten nationalen Gemeinschaften (Teilgruppen) überlassen werden muß.“ Kelsen, ebenda, S. 66.

100 Vgl. Kelsen, Demokratie (Fn. 35), S. 68, wo im Kampf gegen den Marxismus argumentiert wird, erst die parlamentarische Demokratie diene zum Frieden.

101 Vgl. auch Ehs, Einführung (Fn. 26), S. 15 ff. 
„This doctrine refuses to look for the existence of the state in a sphere beyond or above; it finds this existence in the validity and efficacy of a normative order and consequently in the minds of the human beings who are the subjects of the obligations and rights stipulated by this order. This political theory is not directed at an absolutization but, on the contrary, at the relativization of the state. It denounces the concept of sovereignty as the ideology of a definite power policy and hence denies that this concept is applicable in a scientific description of political or legal reality. By demonstrating that absolute sovereignty is not and cannot be an essential quality of the state existing side by side with other states, it removes one of the most stubborn prejudices which prevent political and legal science from recognizing the possibility of an international legal order constituting an international community of which the state is a member, just as corporations are members of the state. This theory shows that the state as a legal community is an intermediate stage in a series of legal phenomena which leads from the universal international community of states, over particular international organizations, to the individual state and from the individual state to the associations incorporated in the state, ending finally with the individual buman being as the legal subject.

It follows from all that has been said before that this anti-ideological, rationalistic, and relativistic political theory corresponds to that intellectual type which has been described as democratic. ... "102

Diese Ausführungen von Kelsen verweisen nicht lediglich auf die demokratischen Anknüpfungspunkte der monistischen Völker- bzw. Europarechtsvorstellung, sondern machen genau dadurch klar, dass die Kelsensche These, die im Grunde genommen durch Pluralismus und Relativismus charakterisiert ist und daher nicht (mehr) vom Gegensatz zwischen Europäisierung und demokratischer Selbstbestimmung ausgeht, der grundgesetzlichen Forderung nach der Verwirklichung eines vereinigten Europas wohl entspricht.

Wenn Art. 23 Abs. 1 GG darauf zielt, die europäische Integration anhand demokratischer und rechtsstaatlicher Grundsätze zu verwirklichen und insofern die innerstaatliche demokratische Ordnung mit der Forderung nach der europäischen Integration in Einklang zu bringen, so ist die pluralistische Demokratietheorie in Verbindung mit einer relativistischen Vorstellung der europäischen Rechtsgemeinschaft besonders geeignet, die gegenseitig unterstützende Beziehung zwischen der Rahmenordnung der Europäischen Union und der demokratischen Ordnung der Mitglied-

102 H. Kelsen, Foundations of Democracy (1955), in: ders., Verteidigung der Demokratie: Abhandlungen zur Demokratietheorie, 2006, S. 248 (295 f.). Ähnlich Kelsen, Staatsform (Fn. 38), S. $52-54$ („In dieser ihrer anti-ideologischen, auf objektiv-wertfreie Erkenntnis gerichteten, alle angeblich absoluten Gegensätze relativierenden Tendenz stellt sich die Rechts-, Staats- und Gesellschaftslehre des demokratischen Typus als die wissenschaftliche Sozialtheorie schlechthin dar ...."). 
staaten zu erklären, indem sie die Demokratie nicht als Verkörperung mehrheitlicher Wertüberzeugungen einer homogenen Gemeinschaft, sondern als die Staatsform versteht und herausstellt, welche die möglichst umfassende Gewährleistung der individuellen Freiheit bezweckt.

Aus dieser Perspektive zeigt sich wiederum deutlich, dass sich die im Lissabon-Urteil hervorgehobene integrationsfeste Verfassungsidentität aus der inhaltsbestimmten, auf Homogenität beruhenden Demokratievorstellung des BVerfG ergibt, die dem grundgesetzlichen Demokratiebegriff in dem Maße entgegensteht, dass unter dem Grundgesetz das Demokratieprinzip und die europäische Integration einander entsprechen, wobei die sich nach außen abgrenzende integrationsfeste Verfassungsidentität in den Hintergrund tritt. Aus Kelsenscher Sicht geht es bei der demokratiefreundlichen europäischen Integration vielmehr darum, im Interesse der individuellen Freiheit grundlegend auf den Staats-Subjektivismus zu verzichten. Demzufolge ist in der Rahmenordnung der europäischen Rechtsgemeinschaft die Staatssouveränität als „rechtliche Zwischenstufe“ 103 keineswegs integrationsfest, sondern im Gegenteil integrationsoffen.

\section{F. Schlussbemerkung}

Im Lichte des Schmitt-Kelsen-Gegensatzes hat die vorstehende Analyse gezeigt, dass die Demokratiekonzeption des Lissabon-Urteils nicht ohne weiteres die normativen Aussagen des Grundgesetzes verkörpert, wie es auf den ersten Blick erscheint. Vielmehr bringt das BVerfG hier - genauso wie in der Maastricht-Entscheidung - die Homogenitätsbedingungen der Demokratie zum Ausdruck und bemüht sich insoweit überwiegend darum, im Namen der Demokratie und der Souveränität die eigene Identität des deutschen Volkes gegenüber der europäischen Integration aufrechtzuerhalten. Auch wenn der Name Schmitt nicht auftaucht, hat sich dessen Einfluss wohl in der Begründung des Lissabon-Urteils niedergeschlagen, indem diese im Grunde genommen vorwiegend auf die Voraussetzung demokratischer Homogenität zurückzuführen ist. Die Gründe dafür, dass das BVerfG an einer statischen Identitätsvorstellung ${ }^{104}$ festhält und dass dabei nicht die Freiheit, sondern in der Tat die für die Verwirklichung demokratischer Selbstbestimmung auf der europäischen Ebene bedeutsame Gleichheit ${ }^{105}$ im Vordergrund steht, lassen sich besonders im Spiegel von Schmitts Thesen kohärent erklären.

Trotz aller Unterschiede stimmt die Stellungnahme des Lissabon-Urteils doch zumindest in einem Punkt mit Kelsens Lehre überein, nämlich in der Überzeugung, „Demokratie ohne Kontrolle“ sei „auf die Dauer unmöglich“. Umstritten bleibt je-

103 Kelsen, Staatsform (Fn. 38), S. 54.

104 So auch die Einschätzung bei Nettesheim, Karlsruher Verkündigung (Fn. 18), S. 113 f., 116.

105 Dies zeigt sich schon bei den Ausführungen des BVerfG zur individuellen Wahlrechtsgleichheit sehr deutlich. Vgl. dazu BVerfGE 123, 267 (340 ff., 371 ff.). 
doch, welche Kontrolle die Demokratie benötigen würde. Das BVerfG geht zwar zutreffend davon aus, dass die parlamentarische Demokratie verfassungsrechtlichen Grenzen und daher verfassungsgerichtlicher Überprüfung unterliegen muss. Mit dem eher politischen und zwar nationalstaatszentrierten Demokratieverständnis lässt es indes außer Acht, dass die demokratische Willensbildung in der Bundesrepublik Deutschland als Bestandteil der europäischen Rechtsgemeinschaft gilt und insofern nicht lediglich an das deutsche Grundgesetz, sondern vielmehr auch an das Unionsrecht gebunden werden muss. In diesem Sinne ist der Bindungscharakter des Grundgesetzes qualitativ nichts anderes als der des Unionsrechts. Unter der (Kelsenschen) Voraussetzung des Primats des Völkerrechts kann für eine demokratische bzw. freiheitssichernde Rechtsordnung nicht mehr die Gegenüberstellung von eigener Identität und supranationalem Durchgriff, sondern in erster Linie die Rahmenordnung und -kontrolle des Unionsrechts im Vordergrund stehen, wonach mit der Aktionsfreiheit der mitgliedsstaatlichen Demokratie deren Verpflichtung zur optimalen Freiheitsverwirklichung folgerichtig hineinkommt.

Demzufolge ist die Entscheidung des BVerfG gegen die Anwendbarkeit des von ihm für identitätsverletzend erklärten Unionsrechts in Deutschland ${ }^{106}$ nicht nur aus universalistischer, sondern auch aus demokratischer Perspektive zu beanstanden. ${ }^{107} \mathrm{Im}$ europäischen Mehrebenensystem zeichnet sich die demokratische Ordnung gerade dadurch aus, dass sie sich nicht mehr durch die identitätsbezogene, sich nach außen abgrenzende Selbstbestimmung der Mitgliedstaaten, sondern vielmehr durch die wechselseitige Kooperation ${ }^{108}$ zwischen den zuständigen Organen, ggf. auch zwischen den Parlamenten verschiedener Rechtsebenen verwirklicht, die in Abkehr vom Staats-Subjektivismus in der Lage sein soll, durch eine umfassendere Einbeziehung verschiedener nationaler Perspektiven ${ }^{109}$ den Wertrelativismus zur Geltung zu bringen und dadurch die Freiheit zu optimieren.

Die vorstehende Analyse soll verdeutlicht haben, dass die Demokratisierungsherausforderung für die Europäische Union genau mit der Zielsetzung einer aus der Kompromissgestaltung erfolgenden optimalen Freiheitsverwirklichung korrespondiert. Insofern geht es bei der institutionellen Demokratisierung auf der europäischen

106 Vgl. BVerfGE 123, 267 (400 f.).

107 Dazu kritisch auch Terhechte, Europäischer Bundesstaat (Fn.60), S.141f.; Ruffert, Grenzen (Fn. 18), S. 1205 f.; Müller-Graff, Lissabon-Urteil (Fn. 90), S. 355.

108 Vgl. auch Nicolaysen, Lissabon-Urteil (Fn.68), S. 31 ff.; Terhechte, Europäischer Bundesstaat (Fn. 60), S. 138.

109 Zum institutionellen Potenzial der Europäischen Union zur pluralistischen Interessenartikulation $M$. Kneuer, Mehr Demokratie in der EU nach dem Lissabon-Vertrag?, in: C. Y. Robertson-von Trotha (Hrsg.), Herausforderung Demokratie, 2011, S. 135 (143f.); Zürn, Bundesverfassungsgericht (Fn. 32), S. 52. 
Ebene ${ }^{110}$ vor allem um die Ermöglichung und Verstärkung eines pluralistischen Interessenausgleichs, wobei nicht die Stimmengleichheit, sondern der Minderheitenschutz im Mittelpunkt steht.

110 Zur Notwendigkeit einer verfeinerten Demokratisierung auf europäischer Ebene vgl. etwa Hatje, Demokratische Kosten (Fn. 66), S. 131, 134; Möllers, Fragmentierung (Fn. 27), S. 165 f.; Thym, Integration (Fn. 22), S. 577. 